\title{
Diagnóstico precoce da infecção articular periprotética do quadril - situação atual, avanços e perspectivas*
}

\section{Early Diagnosis of Periprosthetic Joint Infection of the Hip - Current Status, Advances and Perspectives}

\author{
Luiz Sérgio Marcelino Gomes ${ }^{1,2}$ \\ 1 Faculdade de Medicina de Uberaba, Universidade Federal do \\ Triângulo Mineiro, Uberaba, MG, Brasil \\ ${ }^{2}$ Centro de Estudos do Serviço de Cirurgia e Reabilitação Ortopédico- \\ Traumatológica de Batatais, Batatais, SP, Brasil \\ Rev Bras Ortop 2019;54:368-376.
}

\begin{abstract}
Endereço para correspondência Luiz Sérgio Marcelino Gomes, MD, PhD, Rua 7 de Setembro 466, Centro, Batatais, SP, 14300-000, Brasil (e-mail: marcelin@com4.com.br).
\end{abstract}

\section{Resumo \\ Palavras-Chave \\ - prótese de quadril \\ - biomarcadores \\ - microbiologia \\ - sinais e sintomas}

A infecção articular periprotética (IAP) tem consequências devastadoras sobre a função articular e sobre a taxa de morbimortalidade dos pacientes vitimados por esta grave complicação. Ainda que o diagnóstico precoce seja um dos consensos com importância bem estabelecida, as rotinas de investigação são ainda conduzidas de forma empírica, inconsistente e pouco objetiva em muitos centros de todo o mundo. O presente artigo busca contextualizar a situação atual dos conhecimentos sobre o diagnóstico precoce das infecções articulares periprotéticas, assim como discutir os avanços e perspectivas, dentro de um cenário de sua aplicabilidade rotineira pela equipe médica responsável pelo manejo desta temida complicação.

Periprosthetic joint infection (PJI) has devastating consequences on joint function and on the morbidity and mortality rate of patients who are victims of this serious complication. Although early diagnosis is one of the consensuses with well-established importance, routine workup is still conducted on an empirical, inconsistent, and nonobjective basis in many centers around the world. The present article seeks to contextualize the current state of knowledge about the early diagnosis of PJls, as well as to discuss the advances and perspectives, within a scenario of its routine use by the healthcare team, which is responsible for managing this dreaded complication.

\section{Introdução}

A infecção articular periprotética (IAP) é uma das complicações da artroplastia total do quadril (ATQ) mais temidas, quer pelo cirurgião como pelo paciente, uma vez que sua ocor-

Trabalho realizado na Pró-Reitoria de Pós-Graduação da Universidade Federal do Triângulo Mineiro, Uberaba, MG, Brasil.

(1D) Luiz Sérgio Marcelino Gomes's ORCID is https://orcid.org/00000003-1813-7171.

recebido

29 de Março de 2018

aceito

10 de Julho de 2018
DOI https://doi.org/

10.1055/s-0039-1693138. ISSN $0102-3616$. rência pode resultar em déficits funcionais permanentes da articulação ou até mesmo, em situações mais extremas, por em risco a vida do paciente. Ainda que considerada a progressiva redução da sua incidência, desde uma taxa de até $10 \%$ nos anos $1960,{ }^{1}$ para cerca de 0,5 a $2 \%$ nos dias atuais, podemos observar um aumento crescente do número absoluto de IAPs, como resultado da demanda igualmente crescente dos procedimentos artroplásticos do quadril, a ponto da IAP se tornar, em muitos centros, uma das 3 causas mais frequentes de cirurgias de revisão da ATQ. ${ }^{2}$

Copyright $\odot 2019$ by Sociedade Brasileira License terms de Ortopedia e Traumatologia. Published by Thieme Revnter Publicações Ltda, Rio de Janeiro, Brazil 
Muito embora avanços significativos tenham sido obtidos na profilaxia antibiótica e no melhor conhecimento dos fatores de risco, da fisiopatologia e do papel dos biofilmes nas IAPs, as evidências ainda não são compartilhadas de maneira consensual nas diferentes partes do mundo ou até mesmo em diferentes regiões de um mesmo país. Contudo, resguardadas as controvérsias terapêuticas, predomina o forte consenso sobre a absoluta necessidade do diagnóstico precoce.

O diagnóstico e a intervenção precoces podem mitigar a necessidade de inúmeros procedimentos de repetição, reduzir as sequelas funcionais e, mais notadamente, contribuir para menor taxa de morbimortalidade. Pela ausência de um único teste, considerado como padrão ouro para o diagnóstico de IAP, são levados em conta os achados clínicos, exames de imagem, e as combinações de vários testes, através de biomarcadores sanguíneos, do líquido sinovial (LS), dos tecidos periprotéticos, de fluidos oriundos da sonicação dos explantes e, mais recentemente, através do sequenciamento genético. ${ }^{3}$ Contudo, os princípios do diagnóstico precoce não são aplicados de maneira consistente, uniforme e objetiva em diversos centros, contribuindo assim para uma falha inaceitável dos procedimentos terapêuticos realizados mais tardiamente.

O objetivo do presente artigo é avaliar a situação atual dos conhecimentos sobre o diagnóstico precoce das IAPs, assim como discutir os avanços e perspectivas, dentro de um cenário de sua aplicabilidade rotineira, pela equipe médica responsável pelo manejo desta grave complicação.

\section{Definição de Infecção Articular Periprotética}

Muito embora bastante investigado atualmente, ainda não existe um padrão universalmente aceito para a definição e, portanto, para o diagnóstico da IAP (-Tabela 1). Este é um aspecto bastante relevante, uma vez que pode, por si só, influenciar na identificação precoce e na prevalência reportada da IAP, assim como dificultar a interpretação e a comparação entre os achados de diferentes pesquisas clínicas.

Berbari et $\mathrm{al}^{4}$ estabeleceram como critérios definitivos para o diagnóstico (critérios maiores) a ocorrência de fístula cutânea com a articulação protética e/ou a presença de duas culturas positivas com a identificação de microrganismos (MOs) idênticos, seja no liquido sinovial ou no tecido periprotético, e/ou a presença de processo inflamatório agudo no tecido periprotético, assim como a observação de purulência periprotética. Ainda que a purulência periprotética seja considerada um critério maior para o diagnóstico da IAP na versão prévia da Sociedade de Infecção Musculoesquelética (MSIS, na sigla em inglês), ${ }^{5}$ como também pela Sociedade Americana de Doenças Infecciosas (IDSA, na sigla em inglês), ${ }^{6}$ mais recentemente o Consenso Internacional sobre Infecções Articulares Periprotéticas (CIAP-2013) ${ }^{7}$ não reconhece este achado, seja como critério maior ou até mesmo como critério menor de diagnóstico. De fato, o aspecto de purulência periprotética pode ser observado em outras circunstâncias, não infecciosas, de complicações após a artroplastia do quadril, como nas reações adversas tissulares locais (RATiL), seja como reação de osteólise às partículas de polietileno ( - Fig. 1), ou às partículas metálicas, oriundas da superfície protética metal-metal. Ainda assim, este achado tem sido reconsiderado novamente por inúmeros especialistas no tema como um critério menor a ser avaliado.

A definição atualmente mais utilizada é a proposta pelo ICM-2013, ${ }^{7}$ segundo a qual a fístula articular ou duas culturas positivas com MOs fenotipicamente idênticos, são considerados critérios maiores, ou seja, isoladamente suficientes para o estabelecimento da definição e do diagnóstico de IAP. Por outro

Tabela 1 Critérios diagnósticos de Infecção Articular Periprotética

\begin{tabular}{|c|c|c|c|c|c|c|c|c|}
\hline \multirow[t]{2}{*}{ Critérios Diagnósticos } & \multicolumn{2}{|c|}{ Berbari et al (1998) } & \multicolumn{2}{|c|}{$\begin{array}{l}\text { Sociedade de } \\
\text { Infecção } \\
\text { Musculoesquelética } \\
\text { (MSIS) }^{5}\end{array}$} & \multicolumn{2}{|c|}{$\begin{array}{l}\text { Sociedade } \\
\text { Americana de } \\
\text { Doenças Infeciosas } \\
\text { (IDSA) }^{6}\end{array}$} & \multicolumn{2}{|c|}{$\begin{array}{l}\text { Consenso } \\
\text { Internacional sobre } \\
\text { Infecções } \\
\text { Periprotéticas } \\
\text { (I ICM) }\end{array}$} \\
\hline & $\begin{array}{l}\text { Critérios } \\
\text { maiores }\end{array}$ & $\begin{array}{l}\text { Critérios } \\
\text { menores }\end{array}$ & $\begin{array}{l}\text { Critérios } \\
\text { maiores }\end{array}$ & $\begin{array}{l}\text { Critérios } \\
\text { menores }\end{array}$ & $\begin{array}{l}\text { Critérios } \\
\text { maiores }\end{array}$ & $\begin{array}{l}\text { Critérios } \\
\text { menores }\end{array}$ & $\begin{array}{l}\text { Critérios } \\
\text { maiores }\end{array}$ & $\begin{array}{l}\text { Critérios } \\
\text { menores }\end{array}$ \\
\hline Fístula articular & $x$ & & $x$ & & $x$ & & $x$ & \\
\hline $\begin{array}{l}\geq 2 \text { culturas }+ \text { no LS e/ou } \\
\text { TPP (MO idêntico) }\end{array}$ & $x$ & & $x$ & & $x$ & & $x$ & \\
\hline Purulência periprotética & $X$ & & & $X$ & $X$ & & & \\
\hline $\begin{array}{l}\text { Aumento da VHS e } \\
\text { PCR sanguíneas }\end{array}$ & & & & $x$ & & & & $x$ \\
\hline $\begin{array}{l}\text { Leucocitose no Líquido } \\
\text { Sinovial }\end{array}$ & & & & $x$ & & & & $x$ \\
\hline $\begin{array}{l}\text { Neutrofilia no Líquido } \\
\text { Sinovial }\end{array}$ & & & & $x$ & & & & $x$ \\
\hline $\begin{array}{l}\text { Histologia: Inflamação } \\
\text { do TPP }\end{array}$ & $X$ & & & $\mathrm{X}$ & & $\mathrm{X}$ & & $x$ \\
\hline $\begin{array}{l}\text { Cultura }+ \text { única } \\
\text { (LS ou TPP) }\end{array}$ & & & & $x$ & & $x$ & & $x$ \\
\hline
\end{tabular}

Abreviações: LS, Líquido sinovial; MO, microrganismo; PCR, proteína C reativa; TPP, tecido periprotético; VHS, velocidade de hemossedimentação. 


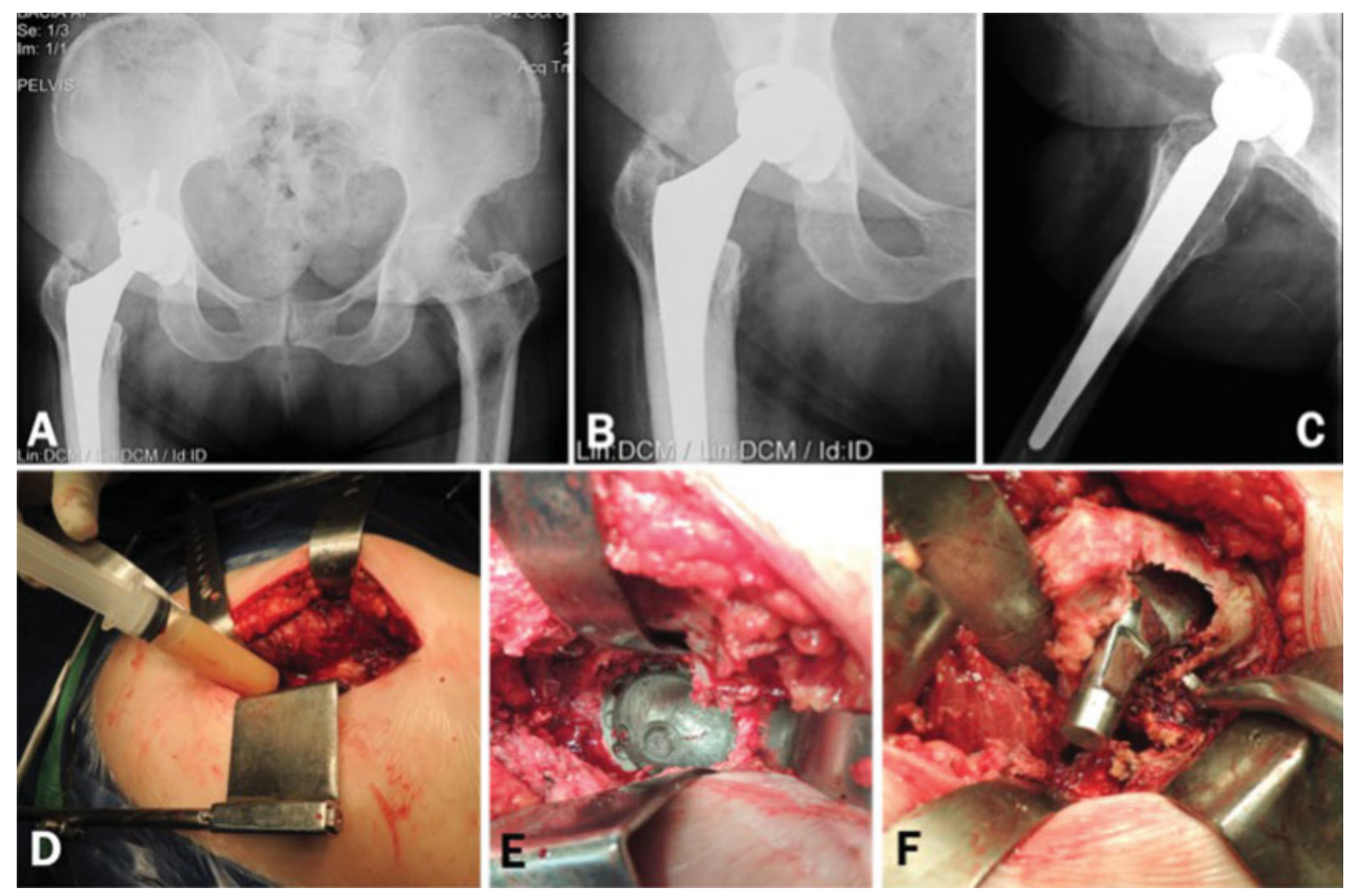

Fig. 1 Paciente assintomático submetido à artroplastia total do quadril ha 4 anos. Radiograficamente observamos o desgaste excessivo do polietileno, não compatível com o período em serviço dos implantes. (Fig. 1 A-C ) Realizamos a cirurgia de revisão a despeito da ausência de manifestações clínicas ou testes indicativos de infecção. Testes pré-operatórios: VHS $=19 \mathrm{~mm}$, PCR $=29.2 \mathrm{mg} / \mathrm{L}$, dimero D $=530 \mathrm{ng} / \mathrm{mL}$ Aspiração intra-operatória do quadril revelou quantidade abundante de liquido de aspecto purulento. (Fig. 1-D ) Não pudemos observar quaisquer sinais de tecidos periprotéticos infectados, soltura acetabular ou abrasão por terceiro corpo. (Fig. 1-E ) Grande área de osteólise foi observada na região posteromedial do fêmur proximal, que se estendia até a região trocantérica. Após a curetagem do tecido esbranquiçado e friável, uma extensa área de perda óssea pôde ser observada no fêmur proximal. (Fig. 1-F ) Testes Intra-operatórios: Esterase leucocitária: +; Leucócitos sinoviais: 52,800; \% de Neutrófilos: 50\%. Todas as 5 culturas de tecido periprotético e 1 cultura de liquido sinovial (em meio de hemocultura) foram negativas após 8 dias de incubação. Até os 18 meses pós-operatórios a paciente mostrou-se assintomático e sem quaisquer alterações nos marcadores séricos para infecção.

lado é preciso que haja a ocorrência de ao menos três dos seguintes critérios menores:

- Velocidade de hemossedimentação (VHS) > $30 \mathrm{~mm}$ para infecções crônicas e proteína C-reativa (PCR) $>10 \mathrm{mg} / \mathrm{L}$ para infecções crônicas ou > $100 \mathrm{mg} / \mathrm{L}$ para infecções agudas;

- Leucócitos no líquido sinovial $>3.000 / \mu \mathrm{L}$ ou esterase leucocitária $+/++$

- Percentual de neutrófilos no LS > 80\%

- Histologia do tecido periprotético com mais de 5 neutrófilos em ao menos 5 campos com aumento de 400x

\section{- Uma cultura positiva}

Quanto aos critérios menores, em que pesem os atuais esforços para a procura de testes mais sensíveis e específicos, ainda não foi possível o estabelecimento de um padrão ouro. Assim, os achados clínicos, como também os mais diferentes marcadores séricos ou do LS, têm sido propostos para o diagnóstico da IAP. Um primeiro fator que pode interferir nos resultados destes critérios está relacionado com a forma de apresentação clínica e com o tempo de aparecimento da IAP. ${ }^{8}$ Este aspecto ressalta a importância da classificação da infecção periprotética no processo de diagnóstico precoce.

\section{Classificação da Infecção Articular Periprotética}

A despeito das inúmeras classificações descritas na literatura, desde a proposta inicial de Coventry, ${ }^{9}$ a classificação de Tsukayama $^{10,11}$ é a mais frequentemente utilizada em pesquisas clínicas. Esta classificação agrega ao modo de apresentação (aguda ou crônica) o período em que os sintomas se desenvolvem após a cirurgia inicial (precoce ou tardio), assim como reconhece não só o modo de infestação por focos à distância (hematogênica ou endógena) ou por inoculação perioperatória do MO (exógena), como também as infecções diagnosticadas pela cultura positiva do LS ou do tecido periprotético em cirurgias de revisão, em pacientes com falha da artroplastia de natureza presumidamente asséptica (-Tabela 2 ). Contudo, existem controvérsias quanto ao intervalo de tempo para a definição de infecções protéticas. Zimmerli et al ${ }^{12}$ propuseram a classificação que considera o tipo precoce, como o que acontece durante os 3 primeiros meses após a cirurgia, o tipo retardado, entre 3 meses e 2 anos, e tardio, após 2 anos do procedimento base. Argumentam os autores que esta distinção se correlaciona com importantes diferenças observadas quanto 
Tabela 2 Classificação de Tsukayama et al (2003) ${ }^{11}$

\begin{tabular}{|l|l|l|l|l|}
\hline $\begin{array}{l}\text { Tipo de Infecção/ } \\
\text { Características }\end{array}$ & $\begin{array}{l}\text { I. Cultura } \\
\text { intraoperatória } \\
\text { positiva }\end{array}$ & $\begin{array}{l}\text { II. Pós-operatória } \\
\text { precoce }\end{array}$ & $\begin{array}{l}\text { III. Hematogênica } \\
\text { aguda }\end{array}$ & IV. Crônica tardia \\
\hline $\begin{array}{l}\text { Início dos sintomas } \\
\text { após cirurgia base }\end{array}$ & - & Até 4 semanas & $\begin{array}{l}\text { Após período } \\
\text { assintomático }\end{array}$ & Após 4 semanas \\
\hline Mecanismo & - & Exógeno & Hematogênico & Exógeno ou Hematogênico \\
\hline $\begin{array}{l}\text { Agente etiológico } \\
\text { mais comum }\end{array}$ & $\begin{array}{l}\text { Estafilococos } \\
\text { coagulase - } \\
\text { (epidermidis) }\end{array}$ & $\begin{array}{l}\text { Estafilococos (Coag + e -) } \\
\text { Bacilos Gram - }\end{array}$ & $\begin{array}{l}\text { Estafilococos } \\
\text { coagulase }+, \\
\text { Estreptococos }\end{array}$ & $\begin{array}{l}\text { Estafilococos (coag + e -) } \\
\text { Bacilos Gram - }\end{array}$ \\
\hline Quadro clínico & $\begin{array}{l}\text { Artroplastia } \\
\text { dolorosa }\end{array}$ & $\begin{array}{l}\text { Febre, sinais inflamatórios, } \\
\text { drenagem persistente, } \\
\text { sem fístula. }\end{array}$ & $\begin{array}{l}\text { Febre, sinais } \\
\text { inflamatórios, } \\
\text { sem fístula }\end{array}$ & $\begin{array}{l}\text { Febre, fístula, drenagem, } \\
\text { purulência, empastamento local }\end{array}$ \\
\hline
\end{tabular}

ao agente etiológico, em que MO mais virulentos, como o Staphylococcus aureus, tendem a ocasionar infecções mais precoces e agentes mais indolentes ou fastidiosos, como o estafilococos coagulase negativo ou o Cutibacterium acnes, as infecções mais tardias.

É possível observar, porém, que a classificação de Tsukayama preenche vários requisitos necessários a uma avaliação adequada das informações mais importantes para a caracterização da IAP. O limite de quatro semanas para a infecção aguda precoce, simultaneamente, delimita um período de recuperação pós-operatória em que a cicatrização da ferida cirúrgica e o desempenho funcional ainda estão em progresso, o valor da PCR aproxima-se dos valores basais, e um possível processo infeccioso ainda não apresenta a consolidação do processo de formação do biofilme. Acresce-se a isto o fato de que os valores de corte para os biomarcadores sanguíneos e sinoviais durante as primeiras 4 semanas são diferentes dos valores de corte após este período. Nesta circunstância, medidas mais conservadoras de tratamento, como a retenção dos implantes protéticos, podem ser justificadas. Já o desenvolvimento de sinais e de sintomas infecciosos após 4 semanas demonstra um caráter de infecções pós-operatórias exógenas em um período em que o resgate funcional e da cicatrização das partes moles já deveriam ter acontecido, ao mesmo tempo em que já transcorreu o tempo necessário para o completo estabelecimento e maturação do biofilme. Desta forma, medidas mais radicais de tratamento devem ser realizadas. Se considerarmos ainda que, para a caracterização de uma infecção hematogênica, é preciso um período pós-operatório assintomático, o tempo de 4 semanas também é suficiente para indicar se houve uma recuperação adequada ou não. Soma-se a isto a distinção da apresentação do quadro clínico em agudo ou crônico, em que se observam diferentes apresentações clínicas, e diferenças quantitativas marcantes dos biomarcadores sanguíneos, do LS, e dos tecidos periprotéticos.

\section{Diagnóstico clínico da Infecção Articular Periprotética (sinais e sintomas)}

Pela ausência de um padrão ouro para o diagnóstico da IAP, baseamo-nos na prática clínica em diretrizes e consensos que se utilizam do quadro clínico e de biomarcadores sanguíneos (menos invasivos) ou do LS, histologia do tecido periprotético e através da bacteriologia, que objetiva a identificação do agente etiológico no LS e nos tecidos periprotéticos, através de culturas pré- ou intraoperatórias, ou até mesmo através de técnicas moleculares. Assim, dentro do contexto diagnóstico da IAP, a prática clínica nos mostra duas dimensões diferentes. O diagnóstico de infecção implica no reconhecimento de um quadro sindrômico de infeção protética que permite diferenciá-lo de outras causas de ATQ dolorosa, ou seja, diferenciar a causa séptica das assépticas, o que possibilita uma intervenção mais precoce. Para isto, utilizamos informações clínicas, de biomarcadores e de imagens. Por outro lado, o diagnóstico da infecção protética implica no reconhecimento do agente ou dos agentes etiológicos, realizado através de culturas de líquidos e tecidos periprotéticos, e mais recentemente através do uso de técnicas moleculares. O conhecimento do agente etiológico irá influir no processo decisório sobre o tratamento mais efetivo. Assim, ao diagnóstico sindrômico deve se seguir uma investigação mais detalhada que nos conduza ao diagnóstico etiológico.

De um modo geral, as informações clínicas apresentam baixa sensibilidade e/ou especificidade para o diagnóstico de IAP, principalmente quando analisadas dentro de um contexto mais amplo, no qual não se considera o período e a forma de apresentação do quadro infeccioso. Para facilitar a identificação e a natureza dos principais sinais e sintomas que possam indicar a origem séptica do quadro de falha da reconstrução protética, nós padronizamos os critérios de: dor, febre, inflamação periprotética (efusão articular, edema, calor local, hiperemia), distúrbios superficiais do sítio cirúrgico (drenagem persistente não purulenta, retardo da cicatrização ou deiscência superficial e localizada da ferida cirúrgica), ou ainda a presença do envolvimento de partes moles profundas (fístula cutânea envolvendo a articulação, supuração ou purulência, abscesso ou a presença de necrose extensa) e distúrbios funcionais da articulação, sob a forma de rigidez ou redução da amplitude de movimentação. ${ }^{13}$

Utilizando esta padronização de sinais e sintomas, recentemente nós realizamos uma revisão sistemática da literatura sobre os achados clínicos da IAP, na qual foram incluídos 4.128 procedimentos artroplásticos infectados. ${ }^{13}$ Observamos que a dor é o sintoma mais sensível, porém com baixa especificidade para o quadro clínico da IAP ( - Tabela 3). Considerando todos 


\begin{tabular}{|c|c|c|c|c|c|c|c|c|c|}
\hline 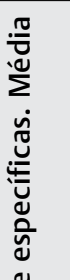 & 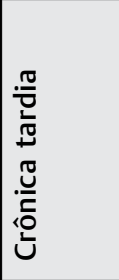 & 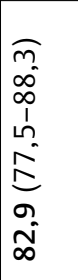 & $\begin{array}{l}0 \\
0 \\
1 \\
7 \\
1 \\
\vdots \\
0 \\
0 \\
0 \\
0 \\
1 \\
1\end{array}$ & 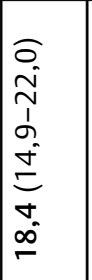 & \begin{tabular}{|l}
$\widehat{N}$ \\
0 \\
0 \\
0 \\
$o$ \\
\\
$\vdots$ \\
$\vdots$ \\
$\tilde{d}$ \\
$\dot{N}$
\end{tabular} & 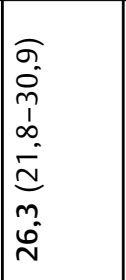 & 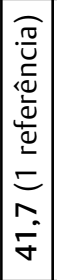 & 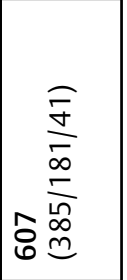 & \\
\hline 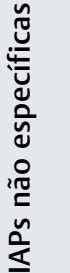 & 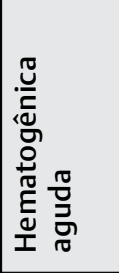 & 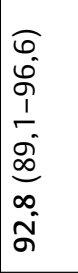 & 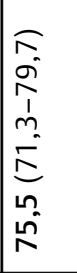 & $\mid \begin{array}{l}\widehat{T} \\
\hat{\sigma} \\
1 \\
1 \\
0 \\
0 \\
0 \\
\hat{0} \\
0 \\
0\end{array}$ & 兴 & $\begin{array}{l}0 \\
\dot{1} \\
1 \\
1 \\
\infty \\
0 \\
0 \\
= \\
=\end{array}$ & 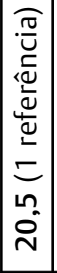 & 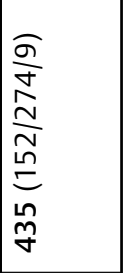 & \\
\hline 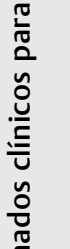 & 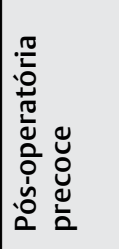 & 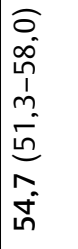 & 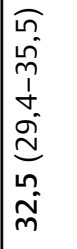 & 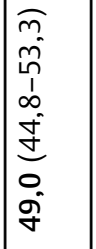 & $\begin{array}{l}0 \\
0 \\
n \\
0 \\
1 \\
b \\
0 \\
0 \\
0 \\
0 \\
0 \\
0\end{array}$ & 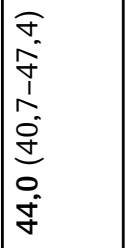 & 受 & 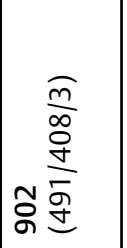 & \\
\hline 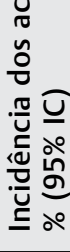 & 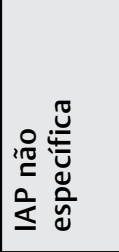 & 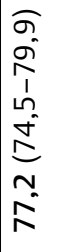 & 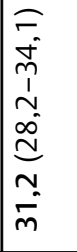 & 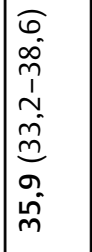 & 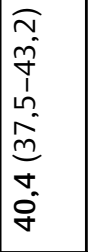 & 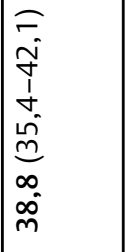 & 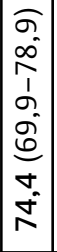 & 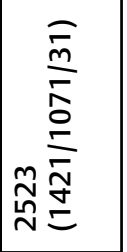 & .்ׁّ \\
\hline & 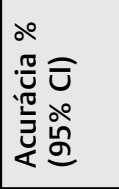 & 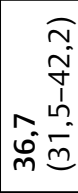 & 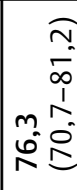 & 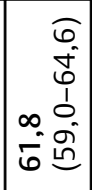 & 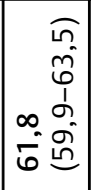 & 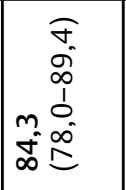 & $\frac{\alpha}{z}$ & 1 & 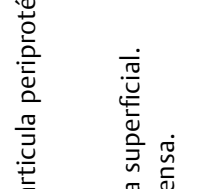 \\
\hline 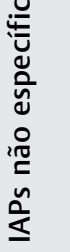 & 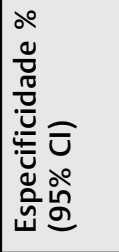 & 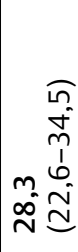 & 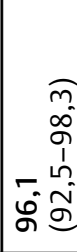 & 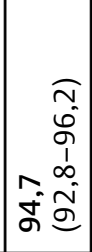 & 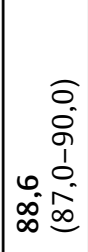 & 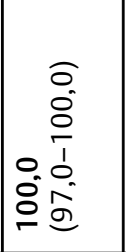 & 兴 & 1 & 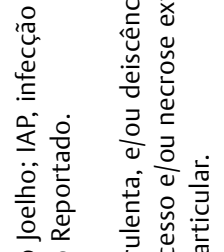 \\
\hline 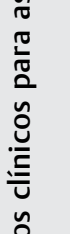 & 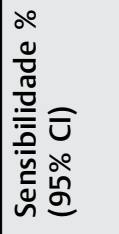 & 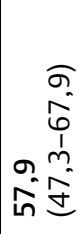 & 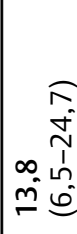 & 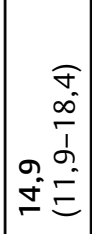 & 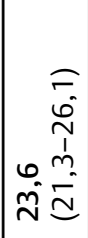 & 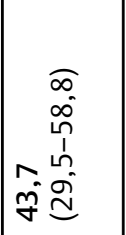 & $\frac{o}{z}$ & | & 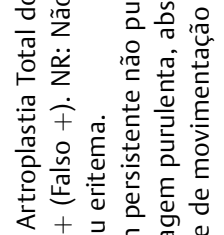 \\
\hline 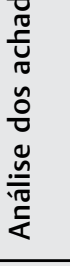 & 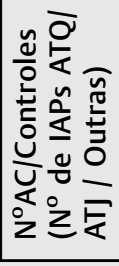 & 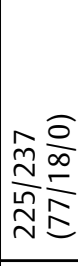 & 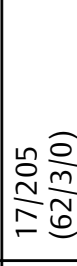 & 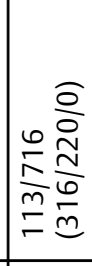 & 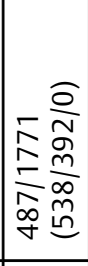 & 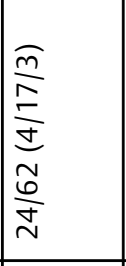 & $\frac{o}{z}$ & 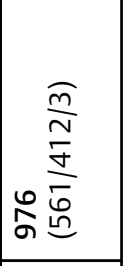 & 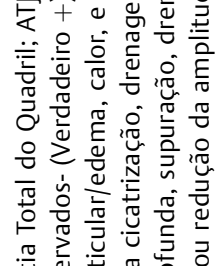 \\
\hline 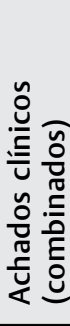 & & ๑ & 这 & 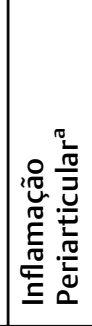 & 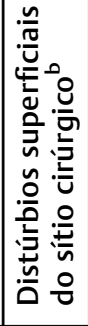 & 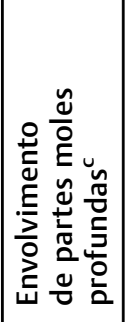 & 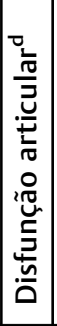 & 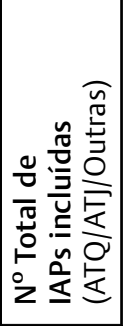 & 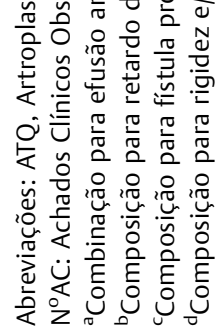 \\
\hline
\end{tabular}


os tipos de IAP em conjunto, somente a dor tem incidência preponderante, enquanto que para os tipos específicos, $a$ infecção pós-operatória precoce tem um quadro clínico caracterizado principalmente pela dor, distúrbios superficiais do sítio cirúrgico, sinais inflamatórios periarticulares e envolvimento de planos mais profundos. A febre tem menor incidência neste tipo de IAP, até porque a hipertermia é comum durante os primeiros 5 dias pós-operatórios, ainda que não se tenha nenhum processo infeccioso de base, sendo portanto uma manifestação do processo de resposta ao trauma cirúrgico. $^{14}$ Os distúrbios funcionais da articulação são subreportados na literatura, o que prejudicou sua avaliação.

A infecção hematogênica aguda, que tem início após um período assintomático da reconstrução protética, se apresenta com um quadro clínico mais frequente de dor de grande intensidade, febre e sinais inflamatórios periarticulares. A concomitância com quadro de bacteremia é responsável por sinais/sintomas sistêmicos de infecção.

Por outro lado, a infecção crônica tardia é marcada por um quadro no qual a dor é o sintoma principal, acompanhado por distúrbios de partes moles periarticulares e disfunção articular. Não infrequentemente, a artroplastia dolorosa, sem outras manifestações marcantes, pode ser a única indicação de IAP crônica tardia, causada por agentes etiológicos de menor virulência. É o que pode acontecer na circunstância de culturas positivas intraoperatórias em cirurgias de revisão com suspeita clínica de causas presumivelmente assépticas, sobretudo quando realizadas em cirurgias com um seguimento $<5$ anos após a cirurgia de base, e nas quais causas mecânicas ou funcionais não podem ser identificadas por investigações convencionais. ${ }^{15}$

É sempre de grande utilidade avaliar os fatores de risco para infecção em pacientes com falha do procedimento artroplástico, uma vez que estes fatores podem estar associados à maior prevalência de IAP, sendo até utilizados como escores para a construção de calculadoras de risco. Mais recentemente, uma análise de 43.253 artroplastias totais, incluindo 1.035 IAPs, identificou como fatores de risco para a infecção, em ordem decrescente de incidência: cirurgia prévia na mesma articulação, abuso de drogas injetáveis, cirurgia de revisão, AIDS, coagulopatia, doença renal, insuficiência cardíaca congestiva, psicoses, doenças reumáticas, artroplastia do joelho, diabetes, anemia, sexo masculino, doença hepática, tabagismo e o índice de massa corporal (IMC). ${ }^{16}$ Reconheceram os autores que estas condições constituem fatores de risco independentes para a IAP.

Desta forma, a partir da suspeição clínica de um quadro sindrômico, ainda que pouco compatível com a IAP, se impõe investigar os marcadores séricos e imagens.

\section{Biomarcadores Séricos no Diagnóstico da Infecção Articular Periprotética}

Biomarcadores sanguíneos têm como objetivo retratar quantitativamente a resposta do organismo ao processo inflamatório/infeccioso subjacente, e para isto se utilizam de um número crescente de proteínas antimicrobianas mais espe- cíficas e citocinas pró-inflamatórias. De um modo geral, os marcadores séricos são preferíveis aos marcadores coletados no LS por serem pouco invasivos, de menor custo, e por permitirem medidas sequenciais e sem o risco de infecções articulares iatrogênicas.

A utilidade da contagem de leucócitos sanguíneos como indicadora de IAP é bastante restrita em função de sua baixa sensibilidade (45\%), à exceção de quadros agudos de IAP hematogênica associados à bacteremia, nos quais a leucocitose pode ser significativa.

Os marcadores séricos mais utilizados como auxiliares no diagnóstico pré-operatório da IAP são a VHS e a PCR.

A VHS expressa somente a velocidade com que as hemácias precipitam-se, o que lhe confere baixa especificidade. Considerando-se um nível de corte de $30 \mathrm{~mm}$, sua sensibilidade é de $75 \%$ e a especificidade de $70 \%$, para uma situação de infecções protéticas crônicas. Na condição de infecções agudas, este exame é considerado inadequado, uma vez que não é possível lhe atribuir um nível de corte confiável. ${ }^{17} \mathrm{~A}$ cinética da VHS após artroplastias eletivas primárias não complicadas mostra um retorno aos níveis basais em média 3 meses após a cirurgia base.

A PCR é uma proteína de fase aguda, que tem sua síntese estimulada por citocinas pró-inflamatórias, como a interleucina 6 (IL-6), porém é também um exame de especificidade restrita. Quando se considera um valor de corte de $10 \mathrm{mg} / \mathrm{L}$, para infecções crônicas, tem-se uma sensibilidade entre 68 e $82 \%$ e especificidade entre 71 e $80 \%{ }^{17,18}$ Nas situações de infecção aguda, considera-se um nível de corte de $100 \mathrm{mg} / \mathrm{L}$. A cinética dos níveis séricos da PCR após artroplastias eletivas primárias não complicadas mostra um retorno aos níveis basais, em média, 3 a 4 semanas após o procedimento cirúrgico.

Saliente-se que tanto a VHS quanto a PCR podem estar elevadas em situações de doenças inflamatórias (falso positivo para infecções) ou estarem normais (falso negativo) em condições de infecções por MO de menor virulência. Ainda assim, a sua utilização na triagem de pacientes suspeitos, para descartar a IAP, é mandatória, uma vez que a sensibilidade e especificidade combinadas destes marcadores são reportadas entre $84 \mathrm{e}$ $98 \%$ e entre 47 e $96 \%$, respectivamente. ${ }^{17-19}$

Outros biomarcadores séricos ainda não têm seu uso corrente padronizado, como a IL-6 ou a interleucina 4 (IL-4). A cinética sérica da IL-6 mostra um pico de elevação em 2 a 3 dias, e um retorno aos níveis normais em cerca de 5 a 7 dias após uma substituição protética não complicada, sendo, portanto um indicador precoce de IAP. Embora tenha uma especificidade de entre 91 e $95 \%$ para um nível de corte de $10 \mathrm{pg} / \mathrm{mL}$, sua sensibilidade é bastante variável nos diferentes estudos (de 47 a 97\%), e assim seu uso ainda não é rotineiro, uma vez que os resultados são discrepantes na literatura, e também é um exame de maior custo quando comparado à VHS e à PCR. Na mesma circunstância se enquadra a $\alpha 1$ glicoproteína ácida.

Outros grupos de citocinas que também apresentam inúmeras ações pró-inflamatórias, como o fator de necrose tumoral alfa (TNF- $\alpha$ ) e a procalcitonina (PCT), secretados pelos monócitos, têm sido apontados como importantes marcadores de infecção, porém os resultados da literatura ainda são conflitantes e, assim, sua utilização clínica 
rotineira ainda não foi estabelecida. Além disso, não há na literatura nenhum estudo com nível de evidência I ou II que indique sua superioridade diagnóstica.

Mais recentemente, Shahi et al reportaram uma perspectiva promissora do uso do dímero D como marcador sérico da resposta aos estímulos inflamatórios, que promovem a elevação sanguínea dos produtos de degradação da fibrina. ${ }^{17}$ Em um estudo que avaliou 172 revisões de artroplastia (86 assépticas e 86 IAPs), os autores encontraram uma sensibilidade de 89\% e uma especificidade de 93\% para o diagnóstico de infecção protética, quando utilizado um nível de corte de $860 \mathrm{ng} / \mathrm{mL}$.

\section{Diagnóstico clínico da Infecção Articular Periprotética. Avaliação por Imagens}

De um modo geral, os exames de imagens têm baixa especificidade para o diagnóstico de IAP e, assim, sua maior utilidade é a de afastar outros distúrbios, não infecciosos, como causa da falha do procedimento artroplástico. As radiografias simples são usualmente normais e, eventualmente, podem apresentar alguns sinais sugestivos de IAP como a soltura e/ou osteólise periprotética em artroplastias com $<5$ anos de duração, elevação subperiostal ou fístula transcortical. Ainda assim, a especificidade do exame radiológico se situa entre 50 e $67 \%$, com uma acurácia de $64 \%{ }^{20}$ Da mesma forma, os exames de ultrassonografia, tomografia computadorizada (TC) e ressonância magnética (RM) não têm relevância direta no diagnóstico de IAP, mas sim por identificar outras causas de falha do procedimento artroplástico.

Os exames de medicina nuclear, como a cintilografia óssea convencional, apresentam grande sensibilidade, porém especificidade muito baixa, o que preclui seu uso rotineiro na investigação da IAP. ${ }^{21}$ Mais recentemente, resultados promissores têm sido reportados com a utilização da imunocintilografia com anticorpos antigranulócitos e com a cintilografia combinada com leucócitos marcados e de medula óssea. Também a tomografia por emissão de pósitrons (PET/CT), utilizando a fluordesoxiglicose ( $\left.{ }^{18} \mathrm{~F}-\mathrm{FDG}\right)$, tem indicação em casos suspeitos de infecção, ainda que sua maior indicação seja na área oncológica. É preciso considerar, contudo, que estes exames são demorados, nem sempre disponíveis e de maior custo.

Desta forma, o papel da imagem nuclear no diagnóstico e tratamento da IAP ainda é incerto, ${ }^{21}$ e de uso mais restrito, uma vez que os métodos aqui já descritos para o diagnóstico sindrômico de infecção são menos invasivos, de baixo custo e amplamente disponíveis.

\section{Biomarcadores no Líquido Sinovial e Histologia do Tecido Periprotético}

A avaliação dos biomarcadores do LS necessita métodos mais invasivos de coleta e, adicionalmente, acrescentam custos e risco de infecção iatrogênica. Acresce-se a isso o fato de que em até $32 \%$ dos procedimentos de punção aspirativa não se consegue quantidade suficiente de líquido para análise. ${ }^{22}$ Por esses motivos, recomenda-se a punção em ambiente cirúrgico e guiado por técnicas de imagem.
Os biomarcadores mais comumente utilizados para o diagnóstico de IAP, a partir do LS, são: contagem total de leucócitos (CTL), percentual de neutrófilos $(\% \mathrm{~N})$, esterase leucocitária (EL), PCR e $\alpha$ defensina. Considera-se, para estes marcadores, um nível de corte de 3.000 leucócitos/ $\mu \mathrm{L}, 80 \%,++, 6.9 \mathrm{mg} / \mathrm{L}$ (nível específico de corte ainda não validado), e positiva para o teste de fluxo lateral, respectivamente.

O exame de $\alpha$ defensina, ainda pouco disponível no Brasil, tem um custo bastante elevado. Considerando a sua positividade no teste de fluxo lateral, a sensibilidade é de $78 \%$, e a especificidade é de $93 \%$. Comparando-se o desempenho dos testes de CTL, \%N e EL, em conjunto com a VHS e a PCR através do método de razão das chances diagnóstica ( $R C D)$, que calcula a razão entre a chance de positividade em pacientes com IAP e a chance de positividade em não infectados, Shahi et al observaram que, para os valores de corte padrão, a EL apresenta o melhor desempenho (30.06 \pm 0.27 ), seguido pela contagem do número de leucócitos (29.45 \pm 0.19 ), PCR (25.66 \pm 0.14$)$, percentual de neutrófilos $(25.53 \pm 0.19)$ e VHS e PCR analisadas em conjunto (23.33 \pm 0.11$).{ }^{23}$ Quando analisada em conjunto com a VHS e a PCR, a EL, se concordante com estes exames, tem uma precisão de $95 \%$ na confirmação ou exclusão do diagnóstico de IAP. ${ }^{24}$

Chama atenção o teste da esterase leucocitária por ser de baixo custo, e que detecta a esterase a partir de fitas utilizadas na análise urinária quando, para uma positividade de + ou ++ , tem sensibilidade de $75 \%$ e especificidade de $91 \%$. Por outro lado, a dosagem da PCR no LS é menos frequentemente utilizada pelo fato da calibração do aparelho destinado à sua dosagem ser diferente da utilizada para os valores séricos. Da mesma forma, a dosagem da IL-6 no LS ainda não foi incorporada rotineiramente à prática clínica.

A histologia dos tecidos periprotéticos, considerada significativa caso se detecte mais de 5 neutrófilos por campo em mais de 5 campos (aumento de 400x), necessita detalhes específicos de coleta e de interpretação, e assim sua utilização rotineira ainda é questionada por alguns autores. Contudo, em um recente estudo sobre a precisão da biópsia de congelação quando comparada aos cortes permanentes, mostrou uma concordância de 97.6\%. Quando avaliada diretamente em relação ao diagnóstico de IAP, a biópsia de congelação demonstrou sensibilidade, especificidade e acurácia de 73.7\% (intervalo de confiança [IC] 95\%: 59.7-87.7\%), de 98.8\% (IC 95\%: 97.1$100.0 \%$ ) e de $94.0 \%$ (IC 95\%: 90.7-97.3\%), respectivamente. ${ }^{25}$

\section{Diagnóstico etiológico das Infecções Articulares Periprotéticas}

\section{Cultura e técnicas moleculares}

A identificação do MO infectante (diagnóstico etiológico) é, sem dúvida, um procedimento de grande importância para que o tratamento adequado seja instituído e, assim, melhores resultados possam ser obtidos. O método convencional de cultura de líquidos e tecidos periprotéticos apresentam um desempenho que ainda não atende às expectativas da equipe médica responsável pelo tratamento das IAPs, com uma alta 
CRITÉRIOS MAIORES: BASTA UM (1)

1. Fistula comunicando com o Quadril $\underline{\mathrm{OU}}$

2. Duas culturas positivas ( Mesmo Fenótipo)
CRITÉRIOS MENORES: $(3 / 5) \quad 1$. VHS> $30 \mathrm{~mm}$ E PCR> $10 \mathrm{mg} / \mathrm{L}$ 2. $>3.000 / \mu \mathrm{L}$ Leucócitos LS $\underline{\text { OU }}$ Esterase Leucocitária + ou ++ 3. Neutrófllos LS > $80 \% \quad$ 4) Histologla $+\quad$ 5) Uma cultura +

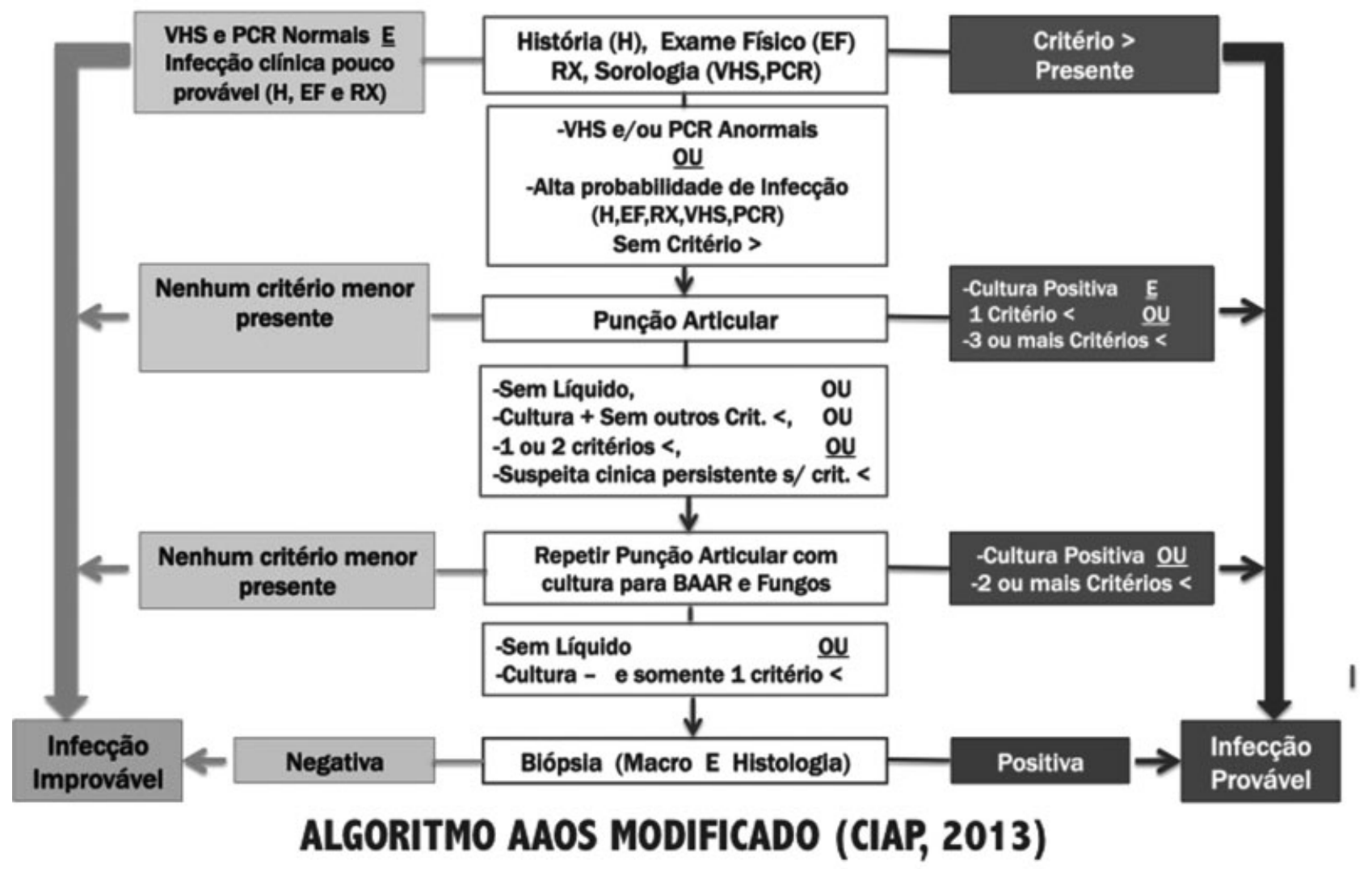

Fig. 2 Algoritmo da Academia Americana de Cirurgiões Ortopédicos modificado (CIAP, 2013) Abreviações: BAAR, bacilos álcool-ácido resistentes; LS, líquido sinovial; CRP, proteína C-reativa; RX, raio-X; VHS, velocidade de hemossedimentação.

taxa de resultados falso negativos, facilmente constatado pela taxa de 5 a $12 \%$ de IAPs denominadas infecções de cultura negativa. ${ }^{26}$

Contudo, grandes desafios diagnósticos podem ser observados nas infecções associadas aos implantes protéticos, como a formação de biofilme, definido por Hall-Stoodley como as infecções causadas por agregados de MO, patogênicos ou oportunistas, encapsulados em uma matriz de exopolissacarídeos, recalcitrantes aos mecanismos de defesa do hospedeiro e ao tratamento antibiótico. ${ }^{27}$ Desta forma, as bactérias livres no tecido periprotético (planctônicas) estão em menor número, e as bactérias em estado metabólico pouco ativo permanecem protegidas no interior do biofilme. Com o objetivo de liberar estas bactérias "dormentes", foi proposta a técnica de sonicação dos explantes, que produz uma agitação mecânica e a consequente liberação bacteriana do biofilme. Mais recentemente, a semeadura do liquido sonicado, ou até mesmo das amostras de tecido periprotético, em frascos para hemocultura, mostrou-se eficaz no aumento da sensibilidade deste teste microbiológico, em até $40 \%$, quando comparado à técnica convencional em Agar ou caldo de tioglicolato (de 44.4 para $60.7 \%$ ), ${ }^{28}$ se considerados os critérios da IDSA para o diagnóstico de IAP. ${ }^{6}$
Outro grande desafio para as culturas tradicionais é a falta de padronização das técnicas de coleta, acondicionamento, transporte e método, e tempo de incubação dos materiais biológicos. Sabe-se atualmente que as bactérias mais indolentes (estafilococos coagulase negativa ou o $C$. acnes por exemplo) podem requerer um tempo de cultura de até 15 dias, em contraste com a tradicional manutenção da incubação por 3 a 5 dias de $\mathrm{MO}$ mais virulentos.

Ainda assim, a prevalência de infecções de cultura negativa permanece significativa e, desta forma, existe um grande empenho no aperfeiçoamento das técnicas moleculares, dentre as quais se destaca o procedimento de sequenciamento de nova geração (SNG). Um recente estudo prospectivo, que incluiu revisões infectadas do quadril ou joelho, constatou que, enquanto as culturas foram positivas em $60.7 \%$ (IC 95\%: 40.6-78.5\%) dos casos, o SNG foi positivo em $89.3 \%$ (IC 95\%: 71.8-97.7\%) dos casos. ${ }^{29}$ Concluem os autores que o SNG é útil na detecção de MO em infecções cultura - assim como na detecção de MO concomitantes que escapam ao reconhecimento nos meios de cultura. Chamam atenção, contudo, para a necessidade de estudos futuros para o esclarecimento da presença de MO isolados de pacientes submetidos a cirurgias de revisão presumidamente assépticas. 


\section{Algoritmo para o Diagnóstico da IAP}

A partir dos principais testes aqui elencados, o ICM-2013 propôs modificações no algoritmo apresentado pela Academia Americana de Cirurgiões Ortopédicos (AAOS, na sigla em inglês, $)^{30}$ o qual orienta, passo-a-passo, a indicação e a interpretação dos testes a serem realizados para a identificação da IAP (-Fig. 2).

\section{Considerações Finais}

A ausência de um padrão ouro para o diagnóstico da IAP do quadril impõe inúmeros desafios ao reconhecimento precoce desta grave complicação, o que pode resultar em maior taxa de falhas do tratamento. Os avanços no conhecimento sobre as IAPs indicam a absoluta necessidade de uma prevenção adequada e sistemática, e do diagnóstico precoce que deve se fundamentar nos achados clínicos, nos biomarcadores sanguíneos e do líquido sinovial, na histopatologia do tecido periprotético, e na identificação do MO infectante, através de culturas e técnicas moleculares. Estes procedimentos devem ser realizados sequencialmente, de forma rotineira e padronizada, em todos os centros que se dedicam ao tratamento das IAPs.

\section{Conflitos de Interesses}

Os autores declaram não haver conflitos de interesses.

\section{Referências}

1 Lidgren L. Joint prosthetic infections: a success story. Acta Orthop Scand 2001;72(06):553-556

2 Ulrich SD, Seyler TM, Bennett D, Delanois RE, Saleh KJ, Thongtrangan I, et al. Total hip arthroplasties: what are the reasons for revision? Int Orthop 2008;32(05):597-604

3 Esposito S, Leone S. Prosthetic joint infections: microbiology, diagnosis, management and prevention. Int J Antimicrob Agents 2008;32(04):287-293

4 Berbari EF, Hanssen AD, Duffy MC, Steckelberg JM, Ilstrup DM, Harmsen WS, et al. Risk factors for prosthetic joint infection: casecontrol study. Clin Infect Dis 1998;27(05):1247-1254

5 Parvizi J, Zmistowski B, Berbari EF, Bauer TW, Springer BD, Della Valle CJ, et al. New definition for periprosthetic joint infection: from the Workgroup of the Musculoskeletal Infection Society. Clin Orthop Relat Res 2011;469(11):2992-2994

6 Osmon DR, Berbari EF, Berendt AR, Lew D, Zimmerli W, Steckelberg JM, et al. Infectious Diseases Society of America. Executive summary: diagnosis and management of prosthetic joint infection: clinical practice guidelines by the Infectious Diseases Society of America. Clin Infect Dis 2013;56(01):1-10

7 Parvizi J, Gehrke T, Chen AF. Proceedings of the international consensus on periprosthetic joint infection. Bone Joint J 2013;95$\mathrm{B}(11): 1450-1452$

8 Fernández-Sampedro M, Fariñas-Alvarez C, Garces-Zarzalejo C, Alonso-Aguirre MA, Salas-Venero C, Martínez-Martínez L, et al. Accuracy of different diagnostic tests for early, delayed and late prosthetic joint infection. BMC Infect Dis 2017;17(01):592

9 Coventry MB. Treatment of infections occurring in total hip surgery. Orthop Clin North Am 1975;6(04):991-1003

10 Tsukayama DT, Estrada R, Gustilo RB. Infection after total hip arthroplasty. A study of the treatment of one hundred and six infections. J Bone Joint Surg Am 1996;78(04):512-523

11 Tsukayama DT, Goldberg VM, Kyle R. Diagnosis and management of infection after total knee arthroplasty. J Bone Joint Surg Am 2003;85-A(Suppl 1):S75-S80
12 Zimmerli W, Trampuz A, Ochsner PE. Prosthetic-joint infections. N Engl J Med 2004;351(16):1645-1654

13 Gomes LSM, Zullo SS, Pereira GA. Response to question Q118 (Hip and Knee): What clinical findings (e.g. fever, erythema, reduced ROM) are most sensitive and specific for the diagnosis of PJI? In: Parvizi, J and Gherke Thorsten. Proceedings of the Second International Consensus Meeting on Musculoskeletal Infections. Brooklandville, Maryland: Data Trace; 2018. p. 343-344

14 Ghosh S, Charity RM, Haidar SG, Singh BK. Pyrexia following total knee replacement. Knee 2006;13(04):324-327

15 Jacobs AME, Bénard M, Meis JF, van Hellemondt G, Goosen JHM. The unsuspected prosthetic joint infection : incidence and consequences of positive intra-operative cultures in presumed aseptic knee and hip revisions. Bone Joint J 2017;99-B(11):1482-1489

16 Tan T, Maltenfort M, Chen A. Development and evaluation of a preoperative risk calculator for periprosthetic joint infection. In: Paper 171 presented at the 2016 Annual Meeting of the AAOS, Orlando, Florida, 2016

17 Shahi A, Kheir MM, Tarabichi M, Hosseinzadeh HRS, TanTL, Parvizi J. Serum D-Dimer Test Is Promising for the Diagnosis of Periprosthetic Joint Infection and Timing of Reimplantation. J Bone Joint Surg Am 2017;99(17):1419-1427

18 Pérez-Prieto D, Portillo ME, Puig-Verdié L, Alier A, Martínez S, Sorlí L, et al. C-reactive protein may misdiagnose prosthetic joint infections, particularly chronic and low-grade infections. Int Orthop 2017;41(07):1315-1319

19 Parvizi J, Fassihi SC, Enayatollahi MA. Diagnosis of periprosthetic joint infection following hip and knee arthroplasty. Orthop Clin North Am 2016;47(03):505-515

20 Aryana K, Hootkani A, Sadeghi R, Davoudi Y, Naderinasab M, Erfani M, et al. (99m) Tc-labeled ubiquicidin scintigraphy: a promising method in hip prosthesis infection diagnosis. Nucl Med (Stuttg) 2012;51(04):133-139

21 Verberne SJ, Raijmakers PG, Temmerman OP. The Accuracy of Imaging Techniques in the Assessment of Periprosthetic Hip Infection: A Systematic Review and Meta-Analysis. J Bone Joint Surg Am 2016;98(19):1638-1645

22 Yee DKH, Chiu KY, Yan CH, Ng FY. Review article: Joint aspiration for diagnosis of periprosthetic infection. J Orthop Surg (Hong Kong) 2013;21(02):236-240

23 Shahi A, Tan TL, Kheir MM, Tan DD, Parvizi J. Diagnosing Periprosthetic Joint Infection: And the Winner Is? J Arthroplasty 2017;32(9S):S232-S235

24 Tarabichi M, Fleischman AN, Shahi A, Tian S, Parvizi J. Interpretation of Leukocyte Esterase for the Detection of Periprosthetic Joint Infection Based on Serologic Markers. J Arthroplasty 2017; 32(9S):S97, 100.e1

25 Kwiecien G, George J, Klika AK, Zhang Y, Bauer TW, Rueda CA. Intraoperative Frozen Section Histology: Matched for Musculoskeletal Infection Society Criteria. J Arthroplasty 2017;32(01):223-227

26 Peel TN, Dowsey MM, Aboltins CA, Daffy JR, Stanley PA, Buising KL, et al. Culture negative prosthetic joint infection.- a description of current treatment and outcomes. Clin Microbiol 2013;2(02):106. Doi: 10.4172/2327-5073.1000106

27 Hall-Stoodley L, Stoodley P, Kathju S, Høiby N, Moser C, Costerton JW, et al. Towards diagnostic guidelines for biofilm-associated infections. FEMS Immunol Med Microbiol 2012;65(02):127-145

28 Peel TN, Dylla BL, Hughes JG, Lynch DT, Greenwood-Quaintance $\mathrm{KE}$, Cheng AC, et al. Improved Diagnosis of Prosthetic Joint Infection by Culturing Periprosthetic Tissue Specimens in Blood Culture Bottles. MBio 2016;7(01):e01776-e15

29 Tarabichi M, Shohat N, Goswami K, Alvand A, Silibovsky R, Belden K, et al. Diagnosis of periprosthetic joint infection: the potential of nextgeneration sequencing. J Bone Joint Surg Am 2018;100(02):147-154

30 Della Valle C, Parvizi J, Bauer TW, Dicesare PE, Evans RP, Segreti J, et al; American Academy of Orthopaedic Surgeons. Diagnosis of periprosthetic joint infections of the hip and knee. J Am Acad Orthop Surg 2010;18(12):760-770 